\title{
Effect of Annealing on the ZnS Nanocrystals Prepared by Chemical Precipitation Method
}

\author{
Nadana Shanmugam, Shanmugam Cholan, Natesan Kannadasan, \\ Kannadasan Sathishkumar, and G. Viruthagiri \\ Department of Physics, Annamalai University, Annamalai Nagar, Chidambaram, Tamil Nadu 608 002, India \\ Correspondence should be addressed to Nadana Shanmugam; quantumgosh@rediffmail.com
}

Received 19 July 2013; Revised 12 October 2013; Accepted 21 October 2013

Academic Editor: Hong Seok Lee

Copyright (c) 2013 Nadana Shanmugam et al. This is an open access article distributed under the Creative Commons Attribution License, which permits unrestricted use, distribution, and reproduction in any medium, provided the original work is properly cited.

\begin{abstract}
Nanocrystals of $\mathrm{ZnS}$ have been synthesized through simple chemical precipitation method using thiourea as sulphur source. The synthesized products were annealed at different temperatures in the range of $200-800^{\circ} \mathrm{C}$. The as-synthesized and annealed samples were characterized by X-ray diffraction (XRD), UV-Visible absorption (UV-Vis), and room temperature photoluminescence (PL) measurements. The morphological features of $\mathrm{ZnS}$ annealed at 200 and $500^{\circ} \mathrm{C}$ were studied by atomic force microscope (AFM) and transmission electron microscope (TEM) techniques. The phase transformation of $\mathrm{ZnS}$ and formation of $\mathrm{ZnO}$ were confirmed by thermogravimetric (TG) and differential thermal analysis (DTA) curves.
\end{abstract}

\section{Introduction}

Wide bandgap semiconductor nanocrystals have attracted the scientific community in the past two decades because of their size dependent properties and diverse applications [1-3]. In semiconductor nanoparticles, bandgap energy can be tuned by slight variation in size and composition, which enables them to be used in variety of applications like photo catalysis, imaging, solar cells, and so forth with an increase in efficiency $[4,5]$. A simultaneous control of structure and morphology of semiconductor nanocrystals provides opportunities to tune and explore their optical properties. Therefore, structure and morphology control are of great interest in the development of semiconductor nanocrystals. Zinc sulphide is a wide bandgap II-VI group semiconductor material of cubic and hexagonal morphologies with bandgaps of $3.72 \mathrm{eV}$ [6] and $3.77 \mathrm{eV}$ [7], respectively, at room temperatures. ZnS has wide range of applications owing to its fluorescence properties [8-13].

Annealing treatments are very common in semiconductor processing. The annealing can be used to improve the crystal quality and to confirm the stability of the crystal at a given temperature, which is important for device purposes. An annealing treatment is quite effective for reproducible size control of $\mathrm{ZnS}$ nanocrystals [14]. In this work, we report the effect of annealing temperature on the structural and morphological properties of $\mathrm{ZnS}$ nanocrystals prepared by simple chemical precipitation method.

\section{Experimental}

2.1. Preparation of $\mathrm{ZnS}$ Nanoparticle. All the chemicals used in this study are of AR grade with $99 \%$ purity (Merck and SD fine chemicals) and used without further purification. Ultrapure water was used for all dilution and sample preparation. Zinc acetate dihydrate $\left[\mathrm{Zn}\left(\mathrm{CH}_{3} \mathrm{COO}\right)_{2} \cdot 2 \mathrm{H}_{2} \mathrm{O}\right]$ and thiourea $\left[\mathrm{CH}_{4} \mathrm{~N}_{2} \mathrm{~S}\right]$ were used as precursors.

The process to prepare Zns nanoparticle is as follows. In this synthesis process, zinc and sulfur sources were taken in 1:1.5 molar ratios. For this $3 \mathrm{~g}$ of zinc acetate in $50 \mathrm{~mL}$ aqueous was stirred magnetically at $80^{\circ} \mathrm{C}$ until homogeneous solution was obtained. Then $3 \mathrm{~g}$ thiourea in $50 \mathrm{~mL}$ of aqueous was added drop by drop to the above solution. After stirring for 2 hours a colorless crystal cleared solution was formed. Then the solution was placed inside a hot air oven at a temperature of $130^{\circ} \mathrm{C}$ for 5 hours and then cooled down to room temperature. The resulting precipitates were filtered off 
and washed several times in water and ethanol and the final products were dried in hot air oven at $80^{\circ} \mathrm{C}$ for 2 hours. The samples were then heat-treated at the rate of $10^{\circ} \mathrm{C} / \mathrm{min}$ for 2 hours and held at temperatures in the range of $200,400,500$, 600 , and $800^{\circ} \mathrm{C}$.

Nanocrystals of $\mathrm{ZnS}$ have been synthesized through simple chemical precipitation method using thiourea as sulphur source. The synthesized products were annealed at different temperatures in the range of $200-800^{\circ} \mathrm{C}$ mentioned above.

2.2. Measurements. The X-ray diffraction (XRD) patterns of the powdered samples were recorded using X' PERT PRO diffractometer with $\mathrm{Cu}-\mathrm{K} \alpha$ radiation $(k=1.5406 \AA)$. The crystallite size was estimated using the Scherrer equation. The optical absorption spectra of all the samples in deionized water were recorded using LAMDA 25 PERKIN ELMER spectrometer. Fluorescence measurements were performed on a VARIAN spectrophotometer. The morphology of the product was observed by Nano Surf Easy Scan 2 atomic force microscope (AFM). High-resolution transmission electron microscopy (HRTEM) analysis was performed using JEOL 3010 HRTEM to study the morphology and size of the nanocrystals. Thermogravimetric analysis (TGA) and differential thermal analysis (DTA) studies have been performed using Perkin Elmer Diamond TGA/DTA instrument at a heating rate of $20^{\circ} \mathrm{C} / \mathrm{min}$ in air.

\section{Results and Discussion}

The XRD patterns of starting material as well as those of annealed samples are recorded in the scan range $2 \theta=10-80^{\circ}$. In the case of starting material, three diffraction peaks at $2 \theta$ values of $28.5^{\circ}, 48^{\circ}$, and $57^{\circ}$ appeared due to reflection from the (111), (220), and (311) planes of the cubic (zinc blende) phase of $\mathrm{ZnS}$ (Figure 1). This result suggests that the crystal structure of the sample is in good accordance with that of the Zinc blende ZnS of the standard card (JCPDS card no-05566). The particle size was determined to be $8.65 \mathrm{~nm}$ from the width of the diffraction peaks corresponding to (111), (220), and (311) planes by using the well-known Scherrer equation:

$$
D=\frac{0.89 \lambda}{\beta \cos \theta}
$$

where $\lambda$ is wavelength of X-ray (1.5406 $\AA$ ), $\beta$ is FWHM in radian, and $\theta$ is Bragg's angle in degree.

From Figure 1 it is clear that, at $200^{\circ} \mathrm{C}$, the sample is still in its cubic phase with broadened XRD peaks. The broadening of the diffraction peaks results from the decrease of particle size. The average particle size was determined to be $5.96 \mathrm{~nm}$. As we increase the temperature to $400^{\circ} \mathrm{C}$, phase transformation of $\mathrm{ZnS}$ has been taken place. As a result of transformation cubic phase of $\mathrm{ZnS}$ is changed into hexagonal $\mathrm{ZnS}$. It is also seen in Figure 1 that at $400^{\circ} \mathrm{C}$ a faint portion of wurtzite $\mathrm{ZnO}$ has been formed and is indicated by the planes (100), (002), and (101).

The XRD patterns of all the four high temperature annealed samples match well with JCPDS numbers 361405 (for hexagonal $\mathrm{ZnS}$ ) and 36-1451 (for hexagonal $\mathrm{ZnO}$ ).

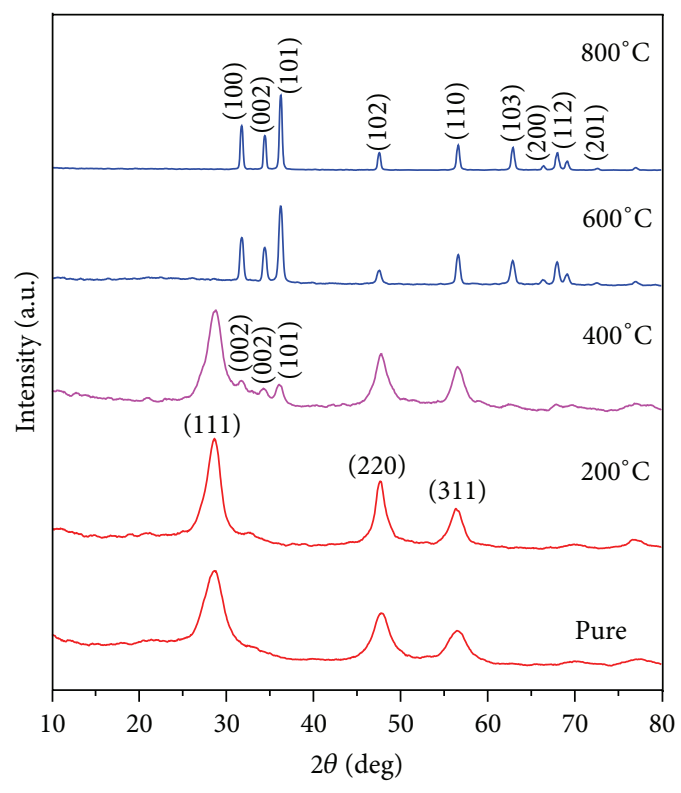

FIGURE 1: XRD patterns of as-synthesized and annealed ZnS.

However, $\mathrm{ZnS}$ wurtzite phase completely disappears and wurtzite $\mathrm{ZnO}$ appeared when the annealing temperature was brought to $500^{\circ} \mathrm{C}$. This result reveals that $500^{\circ} \mathrm{C}$ is the temperature essential to the conversion from $\mathrm{ZnS}$ to $\mathrm{ZnO}$ nanoparticles in the presence of air [15]. The average particle size of the $\mathrm{ZnO}$ was determined from the diffractions peaks and found to be $22.82 \mathrm{~nm}$.

Hence it is concluded that as a result of increase in annealing temperature formation of $\mathrm{ZnO}$ speeds up, and the transformation is completed at $500^{\circ} \mathrm{C}$. On further increase in the annealing temperature up to $800^{\circ} \mathrm{C}$, the diffraction peaks are found to narrow down as compared to those of the samples annealed at $500^{\circ} \mathrm{C}$ indicating the growth of bulk crystallites. The average crystallite sizes are 32.60 and $66.49 \mathrm{~nm}$ for the samples annealed at 600 and $800^{\circ} \mathrm{C}$, respectively.

The optical properties of semiconductor materials are directly determined by the size and shape of the particles. We demonstrated the optical properties of as-synthesized and annealed products using a combination of UV-Visible and photoluminescence (PL) techniques. As shown in Figure 2, absorption peaks around 282, 278, 316, 333, 348, and $367 \mathrm{~nm}$ were noted corresponding to as-synthesized $\mathrm{ZnS}$ and $\mathrm{ZnS}$ annealed at $200,400,500,600$, and $800^{\circ} \mathrm{C}$, respectively. In comparison with the absorption edge of as-synthesized $\mathrm{ZnS}$, the absorption maximum of the sample annealed at $200^{\circ} \mathrm{C}$ was found to be blue-shifted by $4 \mathrm{~nm}$. Such a shift in the optical absorption spectrum is known to take place owing to quantum confinement effect, which occurs in the case of nanoparticles when the particle size becomes comparable with or smaller than Bohr radius of exciton [16]. The ZnS nanoparticles annealed at $200^{\circ} \mathrm{C}$ have size less than the Bohr exciton diameter of $\mathrm{ZnS}$, which is around $5.96 \mathrm{~nm}$. According to the formula $E_{g}=h c / \lambda \mathrm{eV}$, the bandgaps were calculated and are 4.39, 4.46, 3.92, 3.72, 3.56, and $3.40 \mathrm{eV}$, 


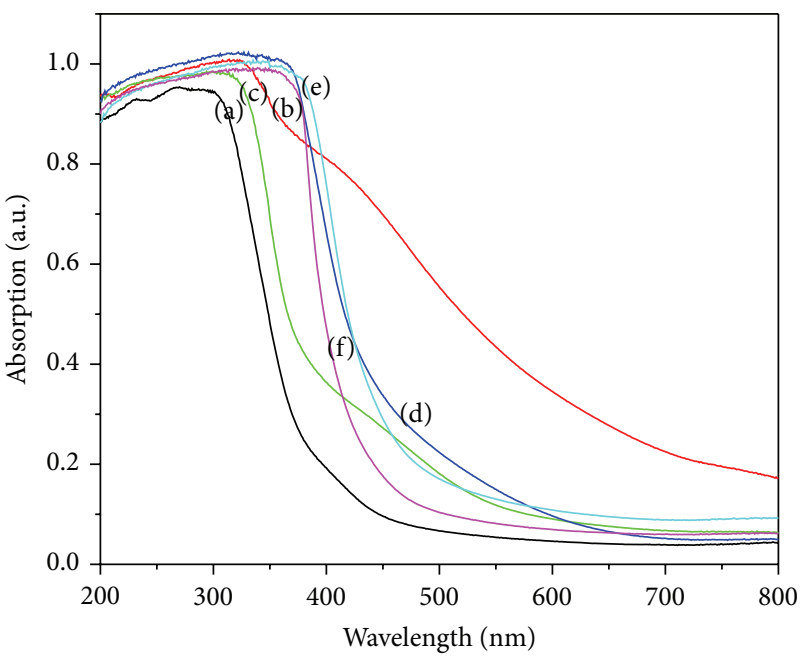
(a) Pure
(b) $200^{\circ} \mathrm{C}$
(d) $500^{\circ} \mathrm{C}$
(c) $400^{\circ} \mathrm{C}$
(e) $600^{\circ} \mathrm{C}$
(f) $800^{\circ} \mathrm{C}$

FIGURE 2: UV-Visible absorption spectra of as-synthesized and annealed $\mathrm{ZnS}$ nanocrystals.

respectively, for as-synthesized $\mathrm{ZnS}$ and $\mathrm{ZnS}$ annealed at different temperatures.

The bandgap of $\mathrm{ZnS}$ annealed at $200^{\circ} \mathrm{C}$ has been increased $(4.46 \mathrm{eV})$ when compared with the bandgap of as-synthesized $\mathrm{ZnS}(4.39 \mathrm{eV})$ as a result of quantum confinement. This result suggests that $200^{\circ} \mathrm{C}$ is the optimum annealing temperature for the harvest of narrow sized $\mathrm{ZnS}$ nanocrystals. In addition, the bandgap value of the sample annealed at $500^{\circ} \mathrm{C}(3.72 \mathrm{eV})$ is higher than that of bulk value of $\mathrm{ZnO}(3.37 \mathrm{eV})$, which confirms the conversion of $\mathrm{ZnS}$ into $\mathrm{ZnO}$ as a result of oxidation of $\mathrm{ZnS}$. However, beyond $200^{\circ} \mathrm{C}$ the bandgap of the samples decreases with increase in annealing temperature.

The room temperature PL spectra of the as-prepared and annealed ZnS nanoparticles are shown in Figure 3. The asprepared $\mathrm{ZnS}$ exhibits three emission peaks positioned at $\sim 349 \mathrm{~nm}, \sim 407 \mathrm{~nm}$, and $\sim 540 \mathrm{~nm}$. The emission at $\sim 349 \mathrm{~nm}$ is attributed to the near-band-edge emission of $\mathrm{ZnS}$ [17]. The peak observed at around $\sim 407 \mathrm{~nm}$ can be attributed to the recombination of electrons at surface sulfur vacancy with the holes at the valance band. The emission at $\sim 540 \mathrm{~nm}$ could be attributed to some self-activated defect centres related to $\mathrm{Zn}$-vacancies [18]. In samples annealed at $200^{\circ} \mathrm{C}$, the PL emission peaks are shifted to higher wavelength regions compared to as-synthesized samples. The shifts in PL peaks are attributed to the variation of bandgap as annealing temperature increases as mentioned in UV-Visible absorption studies. Particularly the peak positioned at $540 \mathrm{~nm}$ in assynthesized $\mathrm{ZnS}$ was shifted $(578 \mathrm{~nm})$ with enhanced intensity. The red shift can be attributed to quantum size effect owing to small particle size and the enhanced intensity reveals that PL spectra are consistent with XRD result of $\mathrm{ZnS}$ annealed at $200^{\circ} \mathrm{C}$.

The emission intensity at $578 \mathrm{~nm}$ may be due to the recombination of electrons from the energy level of sulfur

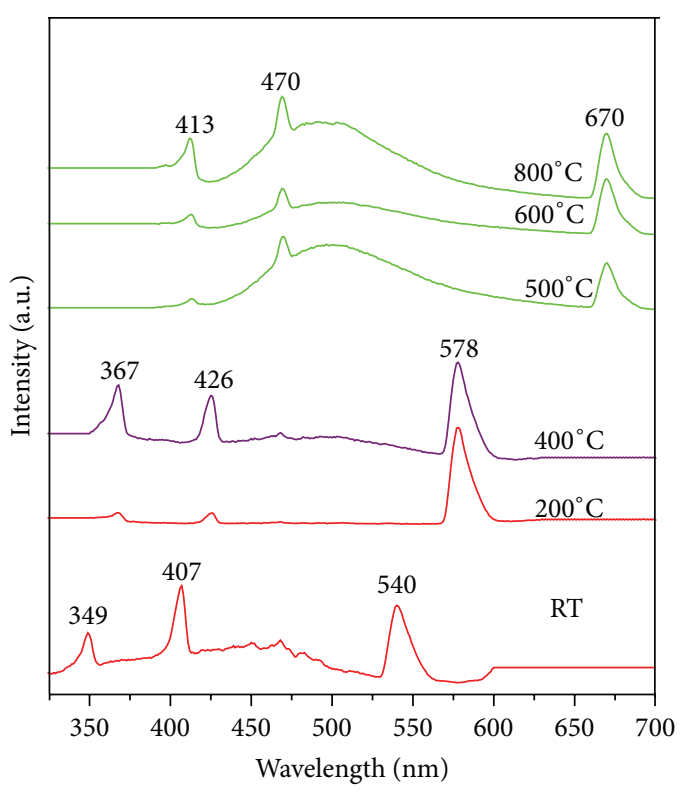

FIGURE 3: PL spectra of as-synthesized and annealed ZnS nanocrystals.

vacancies with the holes from the energy level of zinc vacancies. At an annealing temperature of $400^{\circ} \mathrm{C}$, there is no change in the positions of the peaks but the intensity of them has been enhanced. Further, annealing at $500^{\circ} \mathrm{C}$ revealed three emission peaks at 413,470 , and $670 \mathrm{~nm}$. The emission at $413 \mathrm{~nm}$ is attributed to near-band-edge emission of $\mathrm{ZnO}$ originating from excitonic transitions of between electrons in the conduction bands and the holes in the valence bands [19-21]. The emissions at $470 \mathrm{~nm}$ and $670 \mathrm{~nm}$ are probably ascribed to oxygen vacancies or other defects $[22,23]$. The positions of the emission bands are unchanged as the annealing temperature is raised from 500 to $600^{\circ} \mathrm{C}$ and then to $800^{\circ} \mathrm{C}$. This suggests that these emission bands are weakly associated with the bandgap properties. On the other hand, as far as the intensity is concerned, the intensity of the emission peaks has been enhanced with raise in annealing temperature which means that the oxygen vacancy concentration increases after annealing at high temperatures.

The surface morphology and particle size of the $\mathrm{ZnS}$ annealed at 200 and $500^{\circ} \mathrm{C}$ were studied by AFM. The two- and three-dimensional images of the $\mathrm{ZnS}$ annealed at $200^{\circ} \mathrm{C}$ are shown in Figures 4(a) and 4(b). From the twodimensional view it is noted that most of the particles are well separated from each other and are spherical in shape. The sizes of the particles are in the range of 2.5-27.5 $\mathrm{nm}$. However, most of the particles are in the range of $5-15 \mathrm{~nm}$. The size obtained from the AFM matched well in accordance with the $\mathrm{XRD}$ and TEM results. The $3 \mathrm{D}$ view revealed that the growth direction of all the particles was the same.

Figure 4(c) shows the AFM image of $\mathrm{ZnS}$ nanoparticles after being annealed at $500^{\circ} \mathrm{C}$. As can be seen in the figure, the spherical shape of the nanocrystals does not changes upon annealing, whereas the morphology at the nanoscale exhibits dramatic changes. As a result of high temperature 


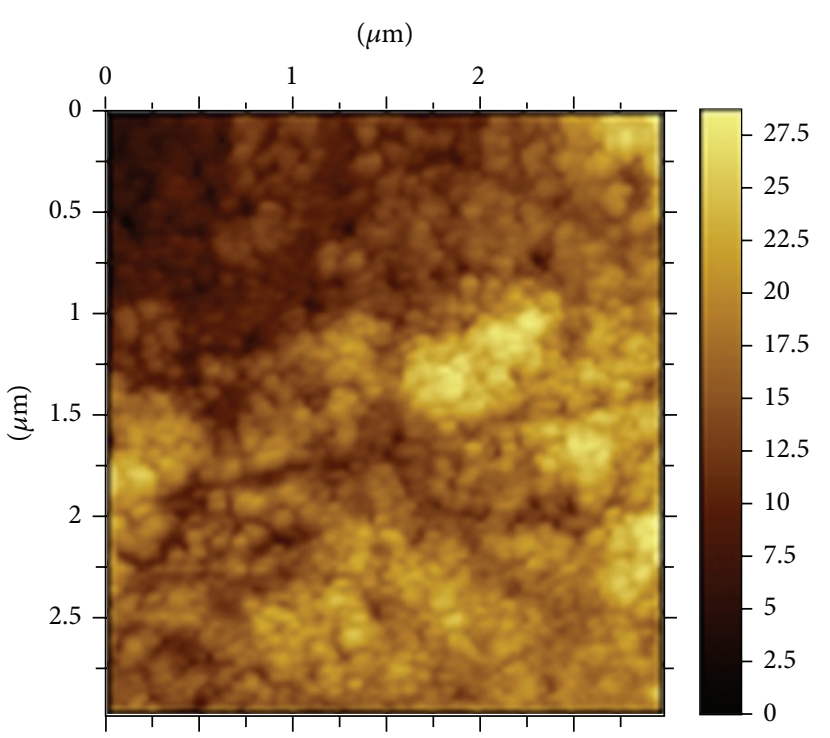

(a)

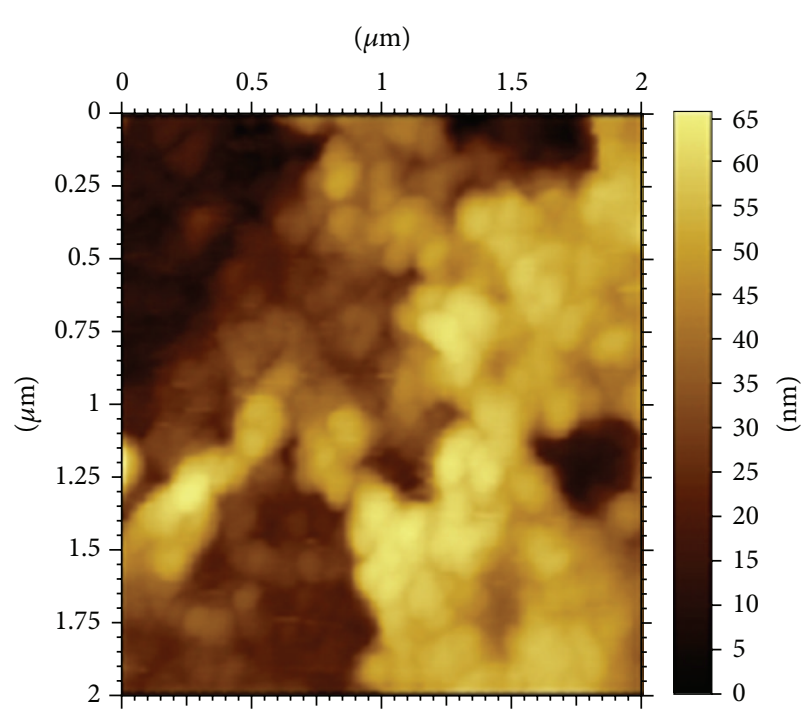

(c)

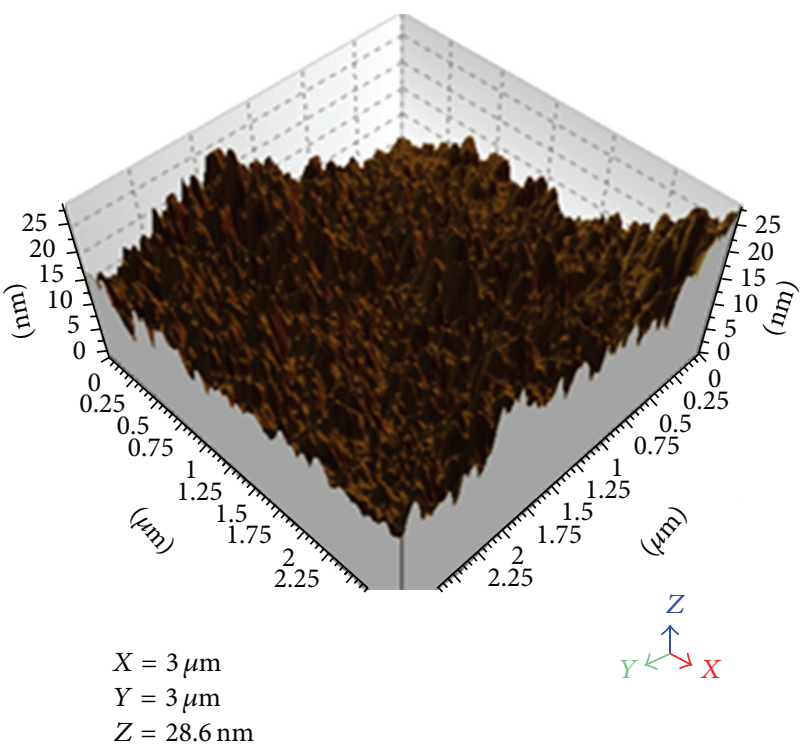

(b)

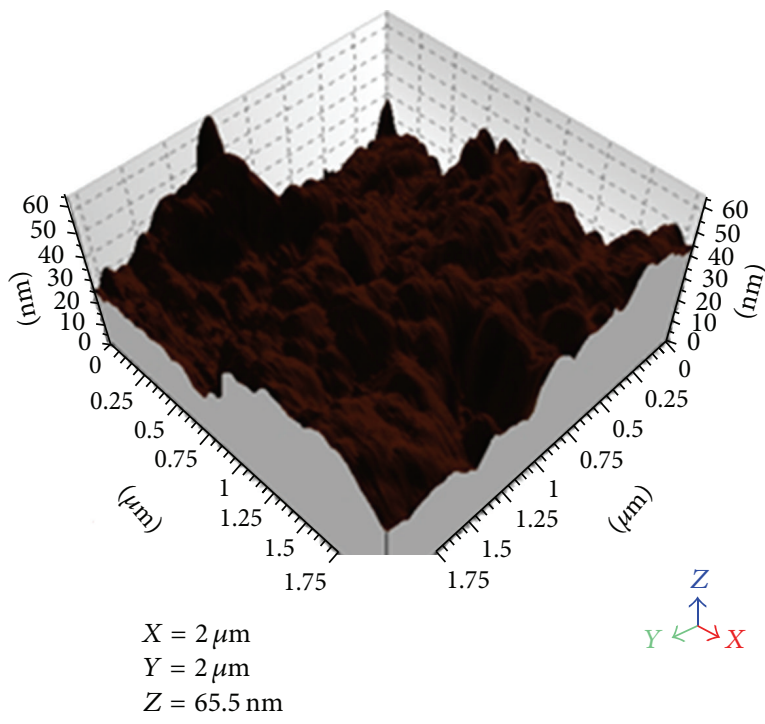

(d)

FIGURE 4: (a) AFM image of $\mathrm{ZnS}$ annealed at $200^{\circ} \mathrm{C}$, (b) corresponding 3D view. (c) AFM image of $\mathrm{ZnS}$ annealed at $500^{\circ} \mathrm{C}$, (d) corresponding $3 \mathrm{D}$ view.

annealing, the size of the particles has been increased due to agglomeration. The size is ranging between 10 and $65 \mathrm{~nm}$. However, most of them are in the range of $30 \mathrm{~nm}$. The $3 \mathrm{D}$ view (Figure 4(d)) exhibits the inhomogeneous growth pattern of the samples.

The morphology and sizes of the nanocrystals are confirmed from TEM studies, as shown in Figure 5. Figure 5(a) indicates the HRTEM image of the samples annealed at $200^{\circ} \mathrm{C}$, revealing the formation of almost monodispersed nanocrystals with average diameter $\sim 2 \mathrm{~nm}$. TEM measurements of $\mathrm{ZnS}$ (Figures 5(b) and 5(c)) annealed at $200^{\circ} \mathrm{C}$ show the agglomerated, nearly spherical particles with size variation between 10 and $15 \mathrm{~nm}$. Figure 5(d) depicts the selected-area electron diffraction (SAED) pattern of the sample annealed at $200^{\circ} \mathrm{C}$. All the diffraction rings were indexed to those of spherical phase of $\mathrm{ZnS}$ in agreement with the XRD patterns. The clear lattice fringes display indicates that the nanoparticles are good crystals. The (111) lattice planes of some particles can mainly be observed and this lattice spacing is estimated to be about $0.310 \mathrm{~nm}$ from HRTEM image, which is consistent with the cubic $\mathrm{ZnS}$ (111) spacing value $(0.312 \mathrm{~nm})$ from standard JCPDS database.

The TEM measurements of $\mathrm{ZnO}\left(\mathrm{ZnS}\right.$ annealed at $\left.500^{\circ} \mathrm{C}\right)$ are shown in Figure 6. Figure 6(a) specifies the HRTEM image of the $\mathrm{ZnS}$ annealed at $500^{\circ} \mathrm{C}$, revealing the formation of $\mathrm{ZnO}$ nanocrystals with diameter $\sim 2 \mathrm{~nm}$. In addition the 

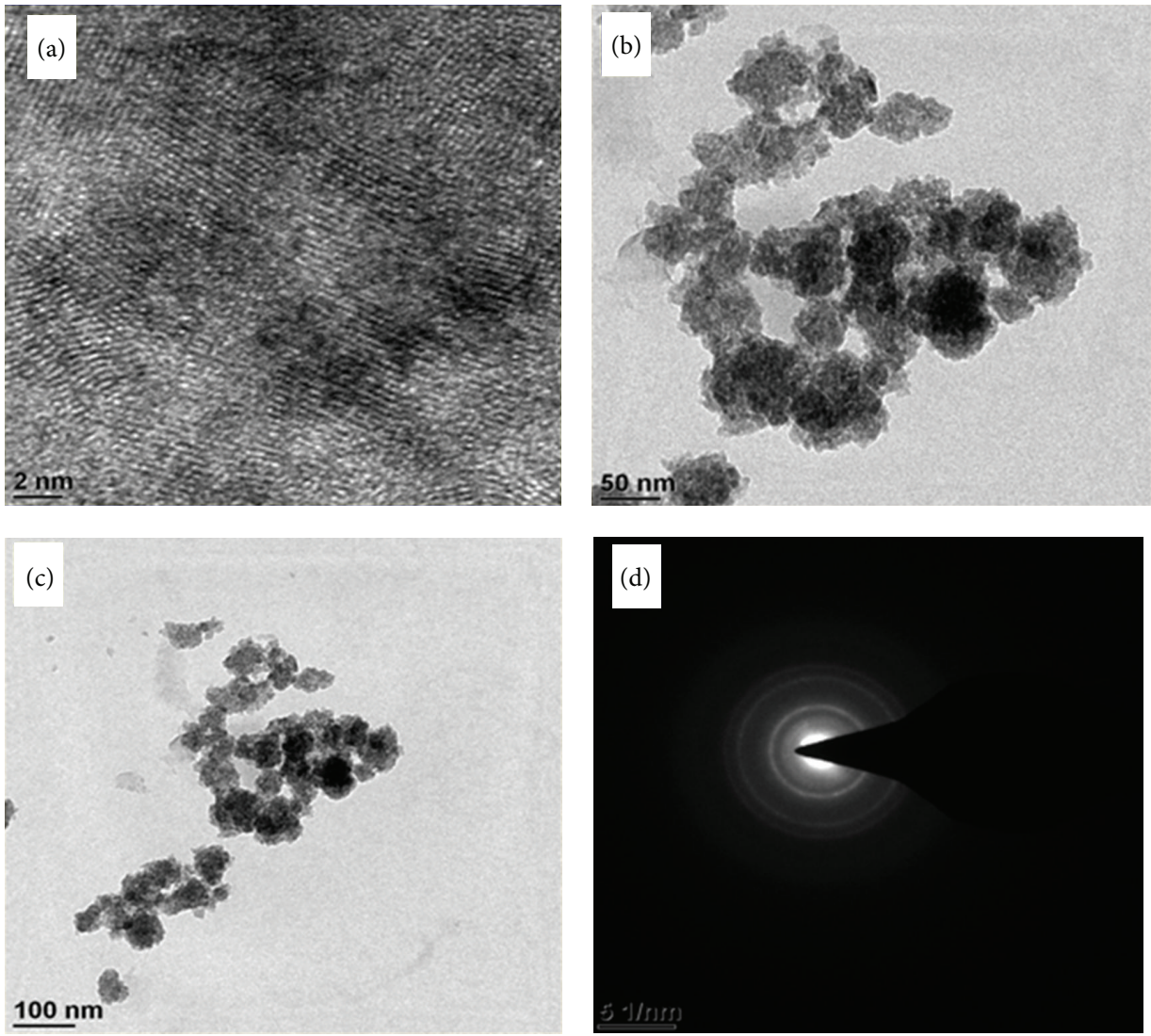

FIGURE 5: (a) HRTEM image of $\mathrm{ZnS}$ annealed at $200^{\circ} \mathrm{C}$, (b), (c) corresponding TEM micrographs, and (d) corresponding SAED pattern.

HRTEM shows that the lattice fringes are separated by a diameter of $0.26 \mathrm{~nm}$, representing the interplanar distance of the (101) lattice plane of $\mathrm{ZnO}$ hexagonal phase. TEM images of the $\mathrm{ZnO}$ show (Figures 6(b) and 6(c)) that the sizes of the individual particles are in the range of 25 to $80 \mathrm{~nm}$. The SAED pattern shows the well-defined electron diffraction spots, confirming the single crystalline nature of the hexagonal phase of $\mathrm{ZnO}$ nanocrystals.

The deviation in the size of the nanoparticles measured by AFM and TEM from Debye-Scherrer calculation may be due to difference in the film preparation and detection technique. When preparing thin flim for AFM or TEM techniques, the smaller nanoparticles may physically contact each other to form larger size particle [24]. It is a well-established fact that precision of crystallite size analysis by Debye-Scherrer calculations, as best, of the order of $\pm 10 \%[25,26]$.

The thermal stability of the synthesized product was investigated by TG-DTA, as shown in Figure 7. The TGA showed four distinct weight losses arising from desorption of water (below $200^{\circ} \mathrm{C}$ ), the decomposition of organic template $\left(200-300^{\circ} \mathrm{C}\right)$, the phase transformation of $\mathrm{ZnS}\left(300-500^{\circ} \mathrm{C}\right)$, and the formation of $\mathrm{ZnO}$ due to oxidation of $\mathrm{ZnS}$ (500$800^{\circ} \mathrm{C}$ ). After $800^{\circ} \mathrm{C}$ there was no weight loss until $1200^{\circ} \mathrm{C}$.

From the DTA curve, there exists an endothermic peak at $180^{\circ} \mathrm{C}$ that may be due to removal of water molecules. A sharp endothermic peak at $220^{\circ} \mathrm{C}$ could be due to the removal of residual organics. As the temperature increases to $340^{\circ} \mathrm{C}$, a small endothermic peak appeared as a result of starting of phase transformation of $\mathrm{ZnS}$. A wide exothermic peak between 300 and $700^{\circ} \mathrm{C}$ with a maximum at $500^{\circ} \mathrm{C}$ was noted. The maximum at $500^{\circ} \mathrm{C}$ explains the formation of $\mathrm{ZnO}$ as a result of oxidation of $\mathrm{ZnS}$. During oxidation enormous amount of energy is released in the form of heat. The wideness of the exothermic peak was due to the growth of the particles and the energy was, therefore released [27]. As the temperature was over $800^{\circ} \mathrm{C}$, the whole system tended to be endothermic. It could be assumed that sulfur atoms escape from the zinc sulfide lattice completely and therefore absorb energy.

\section{Conclusions}

In the present work, the influence of thermal annealing on the structural, optical, and morphological features of $\mathrm{ZnS}$ nanocrystals was investigated. XRD patterns show the formation of $5.96 \mathrm{~nm}$ sized sphere-like cubic $\mathrm{ZnS}$ nanocrystals at $200^{\circ} \mathrm{C}$. However, annealing at $500^{\circ} \mathrm{C}$ in air converts $\mathrm{ZnS}$ into $\mathrm{ZnO}$ as a result of oxidation. UV-Visible absorption peaks suggest that beyond $200^{\circ} \mathrm{C}$ the bandgap of the sample decreases with increase in annealing temperature. The room temperature PL measurements of as-synthesized and annealed samples exhibit that the intensity of the emission peaks has been enhanced with raise in annealing temperature which means that the oxygen vacancy concentration 

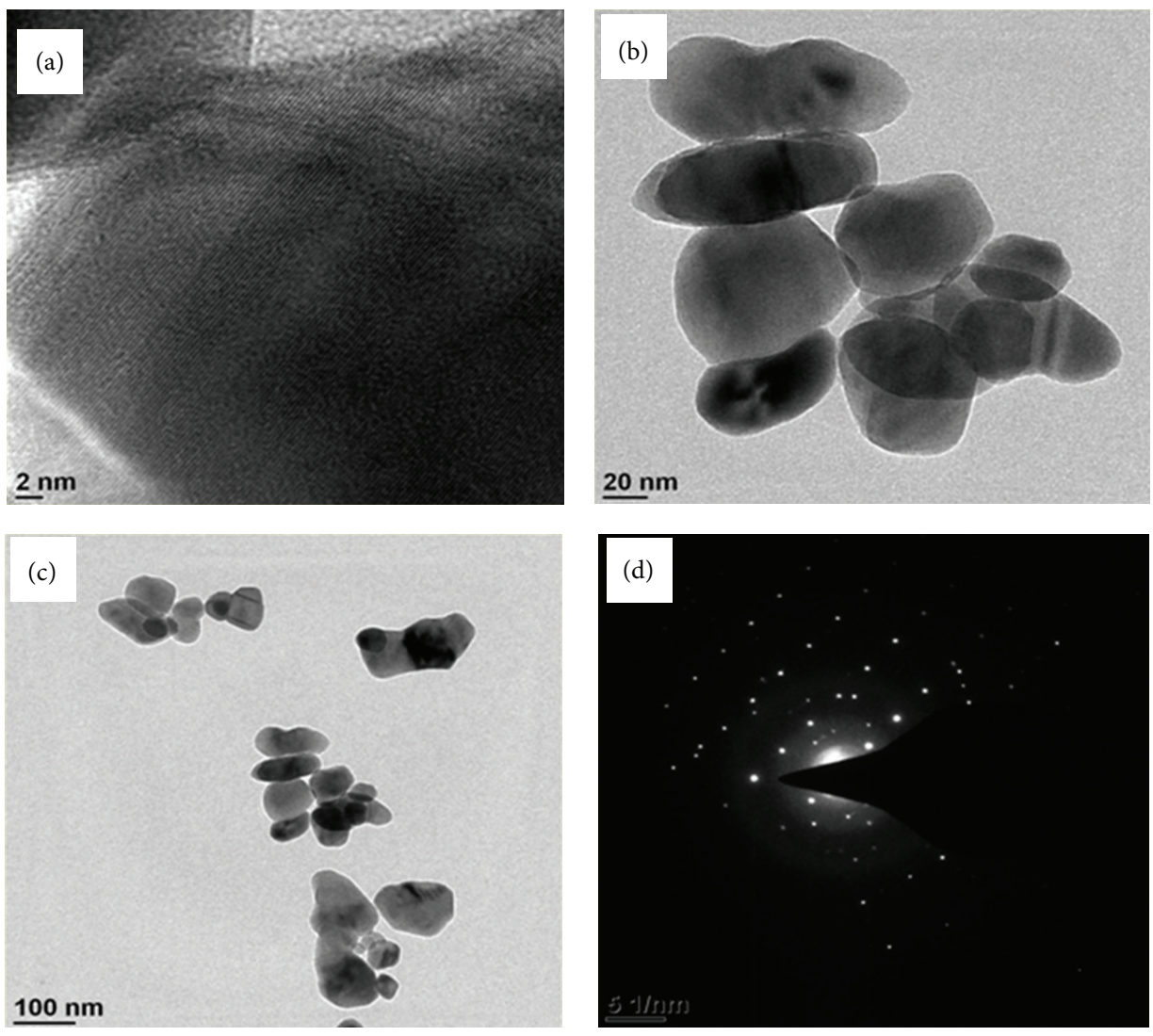

FIgURE 6: (a) HRTEM image of $\mathrm{ZnO}\left(\mathrm{ZnS}\right.$ annealed at $\left.500^{\circ} \mathrm{C}\right)$, (b), (c) corresponding TEM micrographs, and (d) corresponding SAED pattern.

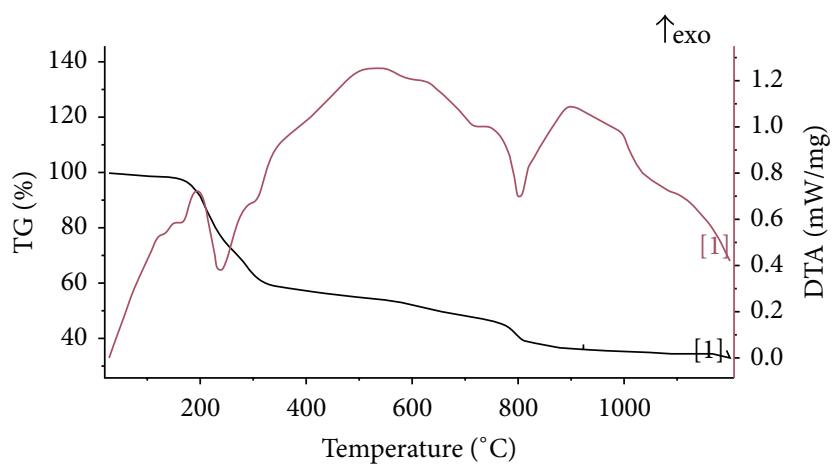

[1] 1.ngb-ds3

- TG

- DTA

FIGURE 7: TG-DTA curves of as-synthesized ZnS nanocrystals.

increases after annealing at high temperatures. The surface morphology of $\mathrm{ZnS}$ and $\mathrm{ZnO}$ was studied by atomic force microscope. The AFM results reveal that particle agglomeration increases with increase of annealing temperature. The periodic layer nanometer structures of $\mathrm{ZnS}$ and $\mathrm{ZnO}$ were identified by high resolution transmission electron microcopy (HR-TEM) images, with thickness of $\sim 2 \mathrm{~nm}$. TEM measurements of $\mathrm{ZnS}$ annealed at $200^{\circ} \mathrm{C}$ show the agglomerated, nearly spherical particles with size variation between 10 and $15 \mathrm{~nm}$, whereas micrographs of the $\mathrm{ZnS}$ annealed at $500^{\circ} \mathrm{C}$ show that the sizes of the individual particles are in the range of 25 to $80 \mathrm{~nm}$. The phase transformation of $\mathrm{ZnS}$ and formation of $\mathrm{ZnO}$ were confirmed by TG-DTA curves.

\section{References}

[1] X. Fang, Y. Bando, U. K. Gautam et al., " $\mathrm{ZnO}$ and $\mathrm{ZnS}$ nanostructures: ultraviolet-light emitters, lasers, and sensors," Critical Reviews in Solid State and Materials Sciences, vol. 34, no. 3-4, pp. 190-223, 2009.

[2] F. Monroy, F. Omnes, and F. Calle, "Wide-band gap semiconductor ultraviolet photo detectors," Semiconductor Science and Technology, vol. 18, pp. 33-51, 2003.

[3] C. Feigl, S. P. Russo, and A. S. Barnard, "Safe, stable and effective nanotechnology: phase mapping of $\mathrm{ZnS}$ nanoparticles," Journal of Materials Chemistry, vol. 20, no. 24, pp. 4971-4980, 2010.

[4] A. P. Alivisatos, "Semiconductor clusters, nanocrystals, and quantum dots," Science, vol. 271, no. 5251, pp. 933-937, 1996. 
[5] P.-C. Kuo, H.-W. Wang, and S.-Y. Chen, "Synthesis and photoluminescent properties of wurtzite $\mathrm{ZnS}$ nanorods by hydrothermal and co-precipitation methods," Journal of the Ceramic Society of Japan, vol. 114, no. 1335, pp. 918-922, 2006.

[6] W. Park, T. C. Jones, W. Tong et al., "Luminescence decay kinetics in homogeneously and delta-doped ZnS:Mn," Journal of Applied Physics, vol. 84, no. 12, pp. 6852-6858, 1998.

[7] H. C. Ong and R. P. H. Chang, "Optical constants of wurtzite ZnS thin films determined by spectroscopic ellipsometry," Applied Physics Letters, vol. 79, no. 22, pp. 3612-3614, 2001.

[8] T. Yamamoto, S. Kishimoto, and S. Iida, "Control of valence states for ZnS by triple-codoping method," Physica B, vol. 308310, pp. 916-919, 2001.

[9] M. Bredol and J. Merikhi, "ZnS precipitation: morphology control," Journal of Materials Science, vol. 33, no. 2, pp. 471-476, 1998.

[10] P. Calandra, M. Goffredi, and V. T. Liveri, "Study of the growth of $\mathrm{ZnS}$ nanoparticles in water/AOT/n-heptane microemulsions by UV-absorption spectroscopy," Colloids and Surfaces A, vol. 160, no. 1, pp. 9-13, 1999.

[11] C. Falcony, M. Garcia, A. Ortiz, and J. C. Alonso, "Luminescent properties of ZnS:Mn films deposited by spray pyrolysis," Journal of Applied Physics, vol. 72, no. 4, pp. 1525-1527, 1992.

[12] W. Tang and D. C. Cameron, "Electroluminescent zinc sulphide devices produced by sol-gel processing," Thin Solid Films, vol. 280, no. 1-2, pp. 221-226, 1996.

[13] C. N. Xu, T. Watanabe, M. Akiyama, and X. G. Zheng, "Artificial skin to sense mechanical stress by visible light emission," Applied Physics Letters, vol. 74, no. 9, pp. 1236-1238, 1999.

[14] T. Kuzuya, Y. Tai, S. Yamamuro, and K. Sumiyama, "Synthesis of copper and zinc sulfide nanocrystals via thermolysis of the polymetallic thiolate cage," Science and Technology of Advanced Materials, vol. 6, no. 1, pp. 84-90, 2005.

[15] D. Amaranatha Reddy, G. Murali, B. Poornaprakash, R. P. Vijayalakshmi, and B. K. Reddy, "Effect of annealing temperature on optical and magnetic properties of $\mathrm{Cr}$ doped $\mathrm{ZnS}$ nanoparticles," Solid State Communications, vol. 152, no. 7, pp. 596-602, 2012.

[16] S. Biswas and S. Kar, "Fabrication of ZnS nanoparticles and nanorods with cubic and hexagonal crystal structures: a simple solvothermal approach," Nanotechnology, vol. 19, no. 4, Article ID 045710, 2008

[17] Y. Li, L. You, R. Duan et al., "Straight ZnS nanobelts with wurtzite structure synthesized by the vapour phase transport process and their crystallization and photoluminescence properties," Nanotechnology, vol. 15, no. 5, pp. 581-585, 2004.

[18] W. Que, Y. Zhou, Y. L. Lam et al., "Photoluminescence and electroluminescence from copper doped zinc sulphide nanocrystals/polymer composite," Applied Physics Letters, vol. 73, no. 19, pp. 2727-2729, 1998.

[19] H.-P. Cong and S.-H. Yu, "Hybrid ZnO-dye hollow spheres with new optical properties from a self-assembly process based on evans blue dye and cetyltrimethylammonium bromide," Advanced Functional Materials, vol. 17, no. 11, pp. 1814-1820, 2007.

[20] S. Yu, C. Wang, J. Yu, W. Shi, R. Deng, and H. Zhang, "Precursor induced synthesis of hierarchical nanostructured ZnO," Nanotechnology, vol. 17, no. 14, pp. 3607-3612, 2006.

[21] R.-Q. Song, A.-W. Xu, B. Deng, Q. Li, and G.-Y. Chen, "From layered basic zinc acetate nanobelts to hierarchical zinc oxide nanostructures and porous zinc oxide nanobelts," Advanced Functional Materials, vol. 17, no. 2, pp. 296-306, 2007.
[22] G. Shen, Y. Bando, and C.-J. Lee, "Growth of self-organized hierarchical $\mathrm{ZnO}$ nanoarchitectures by a simple In/In2S3 controlled thermal evaporation process," Journal of Physical Chemistry B, vol. 109, no. 21, pp. 10779-10785, 2005.

[23] Y. Zhang and J. Mu, "Controllable synthesis of flower- and rodlike $\mathrm{ZnO}$ nanostructures by simply tuning the ratio of sodium hydroxide to zinc acetate," Nanotechnology, vol. 18, no. 7, Article ID 075606, 2007.

[24] N. Goswami and P. Sen, "Photoluminescent properties of $\mathrm{ZnS}$ nanoparticles prepared by electro-explosion of $\mathrm{Zn}$ wires," Journal of Nanoparticle Research, vol. 9, no. 3, pp. 513-517, 2007.

[25] B. D. Cullity, Elements of X-Ray Diffraction, Addison-Wesley, Reading, Mass, USA, 1978.

[26] L. V. Azaroff, Elements of X-Ray Crystallography, McGraw-Hill, New York, NY, USA, 1968.

[27] R. K. Rana, L. Zhang, J. C. Yu, Y. Mastai, and A. Gedanken, "Mesoporous structures from supramolecular assembly of in situ generated ZnS nanoparticles," Langmuir, vol. 19, no. 14, pp. 5904-5911, 2003. 

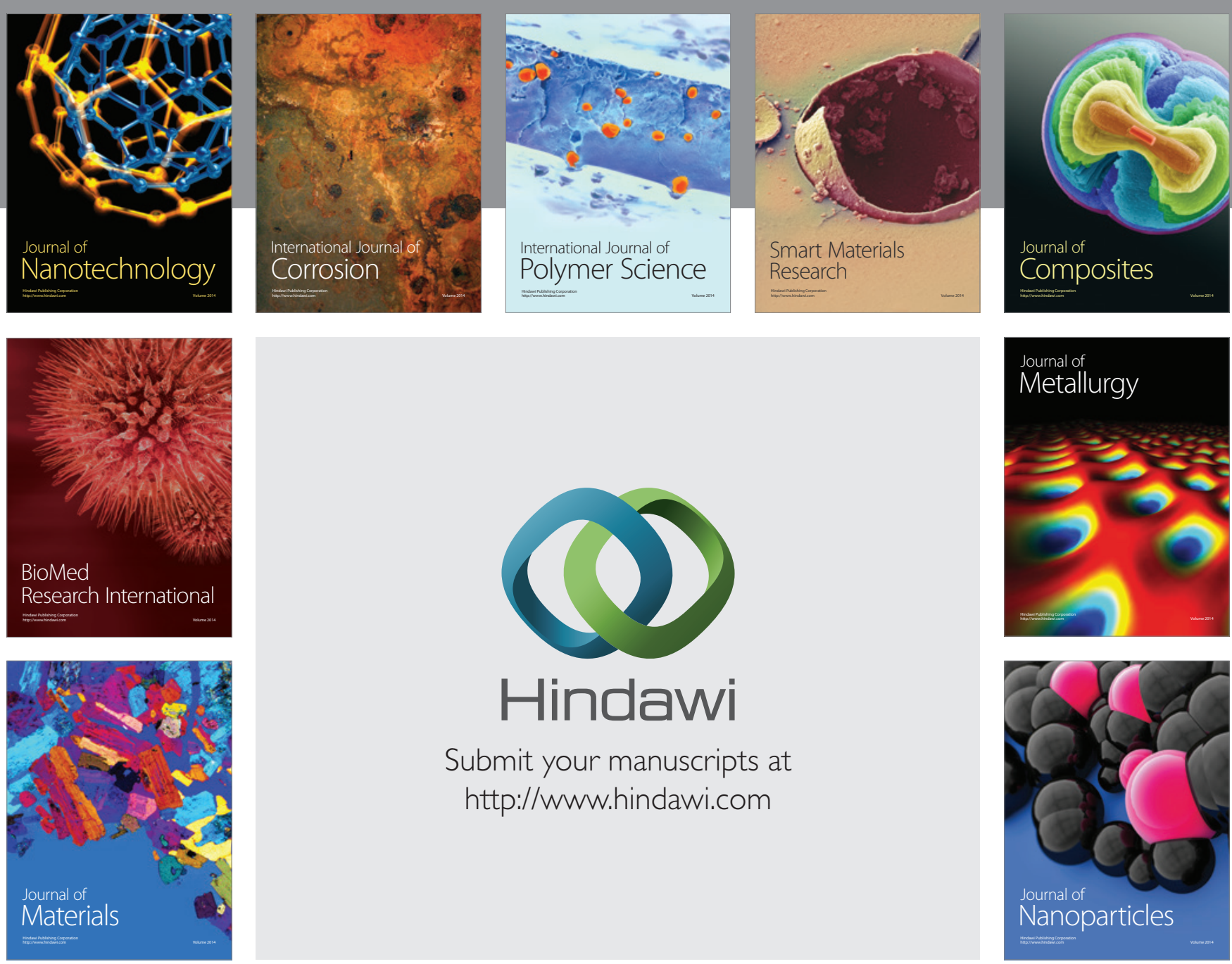

Submit your manuscripts at http://www.hindawi.com
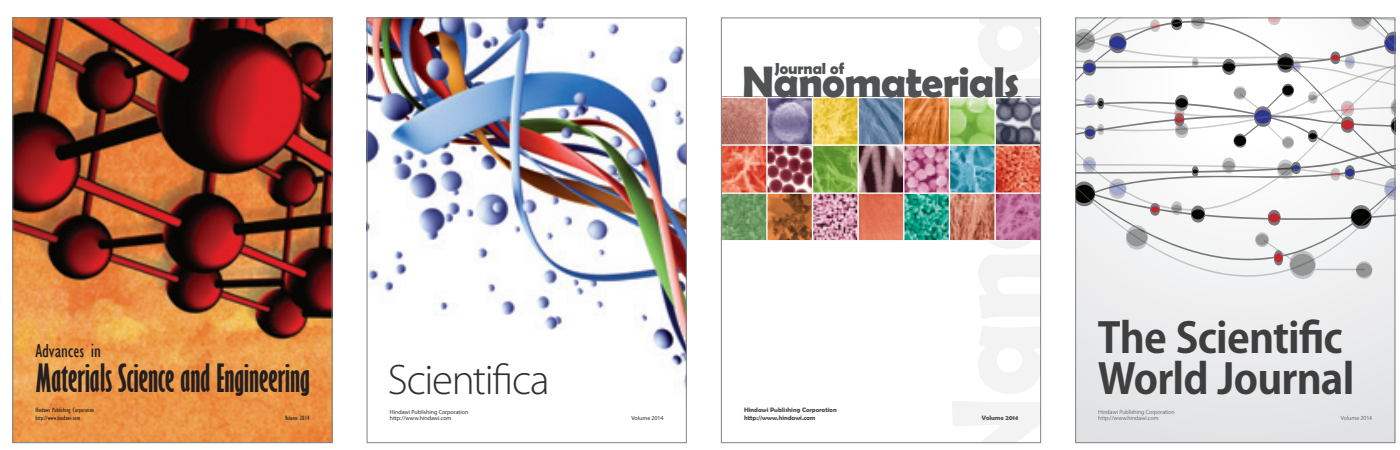

\section{The Scientific World Journal}
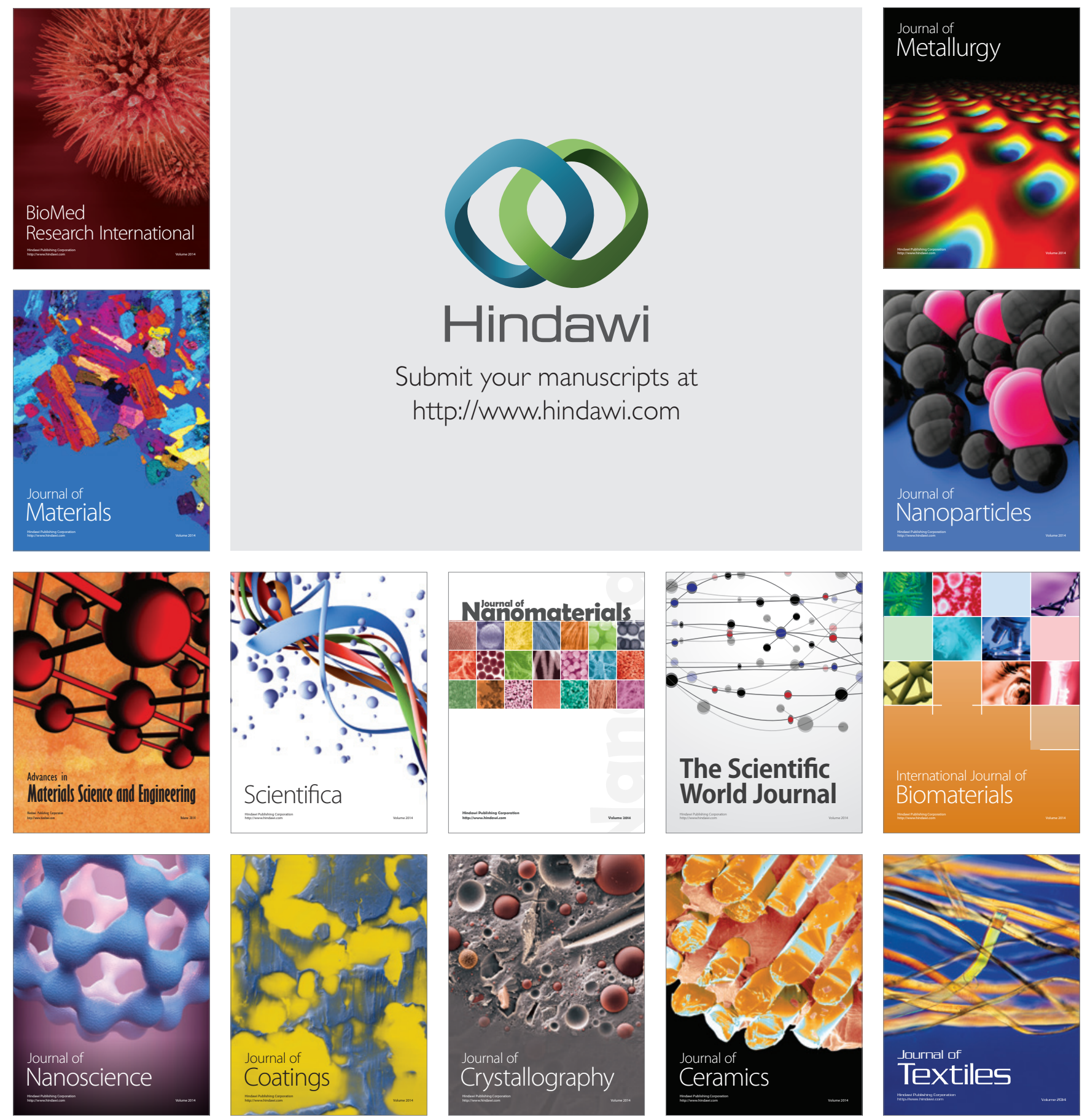